\title{
Hypostatic modifiers cause variation in degree of copper tolerance in Mimulus guttatus
}

\author{
SUE E. SMITH \& MARK R. MACNAIR* \\ Hatherly Laboratories, Department of Biological Sciences, University of Exeter, Prince of Wales Rd, Exeter EX4 4PS, \\ U.K.
}

Previous research into copper tolerance in the monkey flower Mimulus guttatus has found that: (i) it is primarily determined by a single dominant gene; and (ii) there is variation between tolerant plants that has been ascribed to 'modifiers'. Modifiers can be either nonspecific, which act additively on both tolerant (T) and nontolerant (NT) genotypes, or specific, which act only on the tolerant genotype, and are thus hypostatic to the tolerance locus. We show here that there are hypostatic modifiers of tolerance in this species. Two selection lines that differ in degree of tolerance (and thus in the presence of putative modifiers) were crossed to a single NT plant. The $F_{1} s$ were selfed to produce $F_{2} s$ that segregated 3:1 T:NT. NT $F_{2}$ individuals were crossed to a single homozygous $\mathrm{T}$ plant of low tolerance. The families differed in tolerance, showing that the NT $\mathrm{F}_{2}$ individuals differed in genes that only have an effect on tolerance phenotype in the presence of the tolerance gene. $F_{3}$ individuals from $F_{2} s$ of contrasting phenotype were crossed to a second tester tolerant plant, and these $\mathrm{F}_{3} \mathrm{~s}$ also varied, confirming the presence of the specific modifiers. There was no evidence of the segregation that would suggest a single modifier gene, but there is evidence from the $F_{2} s$ of at least one additive, nonspecific modifier in addition to the specific modifiers.

Keywords: copper tolerance, epistasis, Mimulus guttatus, modifiers.

\section{Introduction}

The evolution of metal tolerance by plants growing on abandoned mine sites remains one of the best documented cases of microevolution (see reviews by Antonovics et al., 1971; Baker, 1987; Macnair \& Baker, 1994). The study of the detailed genetics of the phenomenon, however, has lagged behind that of other aspects. Early studies postulated polygenic inheritance (Wilkins, 1960; Antonovics et al., 1971; Gartside \& McNeilly, 1974). However, Macnair (1983) discovered a major gene for copper tolerance in Mimulus guttatus. Following this, there have been a number of papers showing that tolerances to various metals including aluminium, arsenic, boron, cadmium, copper and manganese are under major gene control (see Macnair, 1993 for a review). In many cases, however, the authors have argued that, in addition to the major gene, their data suggested that there were other minor genes ('modifiers') influencing the degree of expression of the tolerance

*Correspondence. E-mail: m.r.macnair@exeter.ac.uk phenotype. The nature and inheritance of these modifiers is little understood.

Macnair (1983) and Macnair et al. (1993), for instance, argued that although there was a single gene for copper tolerance in M. guttatus, some of the variation in level of tolerance, and some of the departures from the predicted Mendelian ratios, might be caused by the presence of modifiers which acted hypostatically to the tolerance gene. Similar arguments were made by Schat \& ten Bookum (1992) and Schat et al. (1993) in their study of copper tolerance in Silene vulgaris. They found a single gene for copper tolerance in most populations of this species, but one highly tolerant population had an additional gene that acted additively with the first. In addition they postulated two modifier loci.

Modifiers are genes that enhance the effect of another gene, and are selected only after the major gene has spread through a population. The major distinction is between specific and nonspecific modifiers (e.g. Endler, 1977; Turner, 1977). Specific modifiers are ones that only affect one genotype, whereas nonspecific modifiers affect all. Thus if the 
major gene is $A / a$ and the modifier $B / b$, then if the phenotype of $a B$ is the same as $a b$, but $A B$ has an enhanced phenotype over $A b$, then $B$ is a specific modifier. In contrast, where $B$ increases the phenotype of both $a B$ and $A B$ over the genotypes $a b$ and $A b$, then it is nonspecific. This is equivalent to whether $B$ acts additively to the $A / a$ locus, or is hypostatic to $A$.

The difference between the two modes of action has important implications for the study of the mechanisms of tolerance, about which we still know very little. A number of mechanisms have been proposed (see Cumming \& Tomsett, 1992; Meharg, 1994) and some authors (e.g. Baker, 1987) have suggested that, because of the manifold effects of metals on plant cells, one would expect a variety of mechanisms to have evolved in any one case of tolerance. Recent work has implicated phytochelatins (Steffens, 1990; Zenk, 1996), metallothioneins (Murphy \& Taiz, 1995) and the cell membrane (de Vos et al., 1989; Strange \& Macnair, 1991). A copper transporter has been isolated in Arabidopsis thaliana (Kampfenkel et al. 1995) whose yeast homologue may be implicated in copper tolerance in the latter organism. If several independent mechanisms have evolved, one would expect their genes to act additively. In contrast, hypostatic action of modifiers would suggest that a single primary biochemical change is needed to produce tolerance, which can be improved and enhanced by the action of other gene changes, but that the molecular products of these other genes cannot produce tolerance independent of the product of the major gene.

Theoretical analyses of disruptive selection at an ecotone (e.g. Endler, 1977) suggest that specific modifiers can spread more easily through a cline than nonspecific. Selection for the major gene on one side of the ecotone, and against it on the other, establishes a cline the steepness of which depends on gene flow and the strength of selection. A specific modifier will spread where it enhances the effects of $A$, but will, if selection only acts on it through its effect on the phenotypes at the $A / a$ locus, be approximately neutral where $A$ is rare or absent. Thus its frequency can become high, under the influence of gene flow, throughout the region of the cline of $A$. In contrast, a nonspecific modifier would be expected to suffer positive selection on one side of the ecotone, and adverse selection on the other, because if it improves the phenotype of $A$, it is likely to impair the phenotype of $a$. Linkage disequilibrium is predicted to build up between major gene and modifier, with a steeper joint cline than would be produced on either gene separately.
Macnair et al. (1993) found clines at the edge of the Copperopolis mine for both the major copper tolerance gene and for the modifiers of tolerance, with the clines for the modifiers appearing to be steeper than those for tolerance per se. A knowledge of the mode of action of the modifiers would assist in the interpretation of this observation.

In order to distinguish between the two types of modifier, it is necessary to test for the presence of genes that act hypostatically to the major gene. In the context of metal tolerance, this means that we have to be able to demonstrate that nontolerant plants, when crossed to a constant tolerant plant, differ reproducibly in their ability to enhance the tolerance of the progeny of these crosses. This paper tests for the presence of hypostatic modifiers for copper tolerance in M. guttatus.

\section{Materials and methods}

\section{Plant material}

IsoT and IsoNT These are plants from the nearly isogenic lines which were produced by repeated backcrossing of the tolerance gene from Copperopolis into a nontolerant genetic background (see Strange \& Macnair, 1991 for details). Briefly, after four generations of backcrossing, heterozygous tolerant plants were selfed and their homozygous and heterozygous tolerant progeny distinguished by a further generation of selfing and progeny testing. Three plants are used in this paper: the IsoT plants (plants E and $\mathrm{J}$ ) are homozygous TT, and the IsoNT plant is homozygous $t$. Note that, because M. guttatus is naturally a primarily outcrossed species, these lines will still be genetically variable at other loci.

Selection lines HT3 and LT3 The Copperopolis population has been selected for increased and decreased tolerance (see Macnair et al., 1993; Harper et al., 1997a, for details of the selection procedure). This produced lines which had diverged in degree of tolerance, but which were both tolerant (and therefore presumed to have the genotype TT).

\section{Tolerance testing}

Tolerance was tested as previously (Macnair, 1983; Macnair et al., 1993). Each individual was tested by the length of roots it was able to form in a solution of $0.5 \mathrm{~g} \mathrm{~L}^{-1}$ of $\mathrm{CaNO}_{3} .5 \mathrm{H}_{2} \mathrm{O}$ with $\mathrm{Cu}$ added as $\mathrm{CuSO}_{4}$. Testing at 0.5 p.p.m. $\mathrm{Cu}$ permits the distinction between tolerant $(\mathrm{T})$ and nontolerant plants (NT): NTs form very poor roots (which are less than about $3 \mathrm{~mm}$, and characteristically brown and 
stunted) whereas Ts form roots of normal appearance which are generally longer than $5 \mathrm{~mm}$. Testing at 1.00 p.p.m. increases the discrimination between the degree of tolerance shown by $\mathrm{T}$ plants (Macnair et al., 1993), with $T T$ and $T t$ plants of lower tolerance rooting poorly at this concentration.

\section{Crossing programme (see Fig. 1)}

$F_{1}$ After three generations of selection, 12 plants from LT3 and 10 plants from HT3 were crossed to the IsoNT. The resulting 22 families were labelled 1-12 (LT3) and 13-22 (HT3), and were grown up and tested for tolerance at 1 p.p.m. $\mathrm{Cu}$.

$F_{2}$ Five plants from each of eight $\mathrm{F}_{1}$ families $(1,2$, $3,10,13,16,17,22$ ) were chosen (both individuals and families at random), grown up and selfed. All five plants from family 2 proved to be male-sterile, but the selfed progeny of one plant from each of the other seven families were grown up and tested at

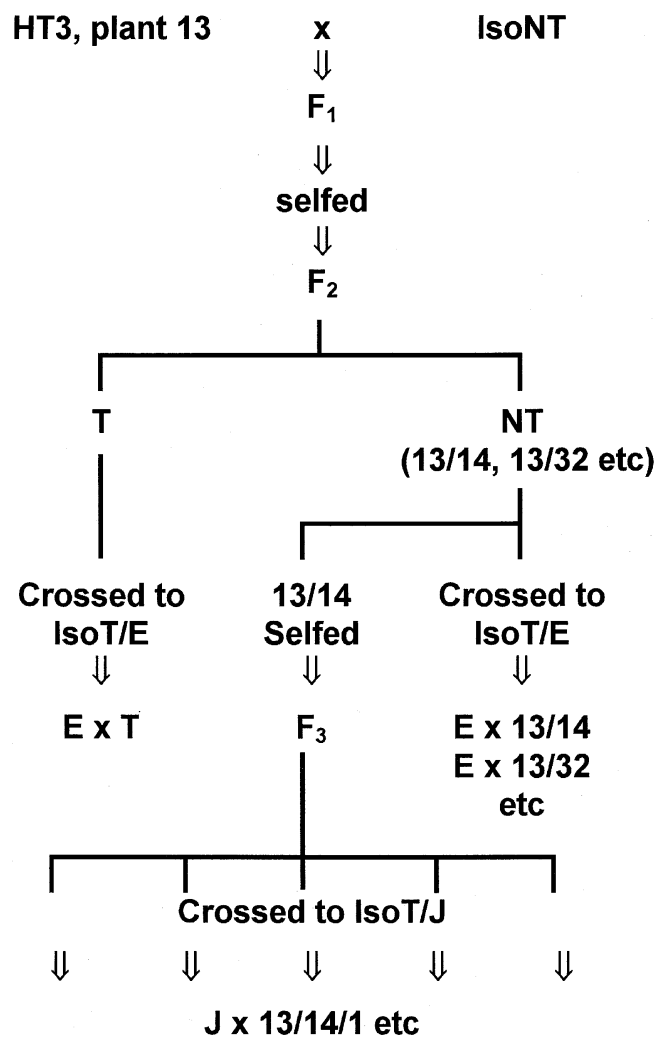

Fig. 2 All plants were grown in cocofibre in plastic pots in Fig. 3 (1983) under short days $(8 \mathrm{~h}$ ). Individual trays were

Fig. 4

Fig. 5

Fig. 1 Diagram illustrating the crossing programme. The crosses derived from a single plant from the HT3 line (plant 13) are illustrated; six other plants from the HT and LT lines were treated similarly. The figures which display the data from each generation of crosses are also indicated. the Exeter University greenhouses, and fed twice weekly with Vitax plant food. Families for tolerance testing were grown in $35 \times 24 \mathrm{~cm}$ trays as in Macnair randomized in the greenhouse. Plants to be crossed were grown under short days until established, and then transferred to long days $(16 \mathrm{~h})$. Flowers were emasculated on the day of anthesis by touching the sensitive stigma with a sterile pair of forceps, and removing corolla and undehisced stamens after the stigma had closed. Stigmas which are free of pollen reopen after about $30 \mathrm{~min}$, and crossing is effected by brushing the anthers of the male parent across the stigma.

0.5 p.p.m. These families segregated $\mathrm{T}$ and $\mathrm{NT}$

Crosses involving $F_{2}$ plants The $\mathrm{NT}_{2} \mathrm{~S}$ were grown up to flowering and both crossed to plant $\mathrm{E}$ (IsoT) and selfed. A random sample of $\mathrm{T}_{\mathrm{F}_{2}} \mathrm{~S}$ were also crossed to plant $\mathrm{E}$. A selection of $\mathrm{E} \times \mathrm{F}_{2}$ families (31 NTs, 11Ts) were grown up and tested at 1.0 p.p.m.

Crosses involving $F_{3}$ plants Five plants from the selfed progeny of each of six NT plants tested in the
$\mathrm{F}_{2}$ crosses above were grown up and crossed to plant $\mathrm{J}$ (IsoT). The $\mathrm{F}_{3}$, the crosses to $\mathrm{J}$, and the selfed progeny of $\mathrm{J}$, were grown up and tested as before.

\section{Plant and cross nomenclature}

Plants are identified by a code (e.g. 1/20/5) in which second number (20) the $\mathrm{F}_{2}$ individual; and the third (5) the $F_{3}$ individual. Crosses are always shown as female $\times$ male.

\section{Plant cultivation and crossing}

\section{Analysis}

Differences in mean root length between families were analysed by ANOVA, following Sokal \& Rohlf (1995). A hierarchical model is used, with original cross nested within line, and $F_{2}$ (or $F_{3}$ ) family nested within original cross. Note that, because of the experimental design used (necessitated by the very large numbers of individuals to be grown), the difference between families within cross compounds both genetic and environmental effects, but the between-original-cross term tests genetic differences only. A log transformation (of root length +0.5 ) was

(c) The Genetical Society of Great Britain, Heredity, 80, 760-768. 
used, which rendered the residuals approximately normally distributed.

\section{Results}

$\mathrm{F}_{1}$

The $22 F_{1}$ families differed in tolerance at 1 p.p.m. $\mathrm{Cu}$ with the 12 families derived from LT3 plants having substantially lower mean root length $(\llbracket=4.60$, range in family mean $1.9-7.8 \mathrm{~mm})$ than any of the 10 families derived from HT3 $(\varangle=22.03$, range in means $12.5-27.6 \mathrm{~mm}$ ). This difference between LT3 and HT3 families is highly significant $\left(F_{1,20}=179.1, P<0.001\right)$. The overall $F_{1}$ distribution is given in Fig. 2.

\section{$\mathrm{F}_{2}$}

Of the seven $\mathrm{F}_{2}$ families tested, only one had a T:NT ratio that differed significantly from $3: 1$ (family 1 ; 22T:20NT, $\left.\chi_{1}^{2}=11.46, P<0.001\right)$. This pattern is one also found by Macnair (1983) and discussed and analysed there. The overall ratio in all families is 254:97 which does not differ from 3:1 $\left(\chi_{1}^{2}=1.3\right.$, NS). This confirms that both HT and LT lines had only the single major gene for tolerance. Figure 3, however, shows the distribution of root lengths of all $\mathrm{F}_{2}$ individuals tested. The segregation into $\mathrm{T}$ and NT is obvious but the graph shows two other patterns: (i) in the $\mathrm{F}_{2} \mathrm{~s}$ of the families derived from HT, 12 of the NT plants have root lengths of 3 or $4 \mathrm{~mm}$, whereas only one plant classified as NT from the corresponding LT $\mathrm{F}_{2} \mathrm{~S}$ has a root length longer than

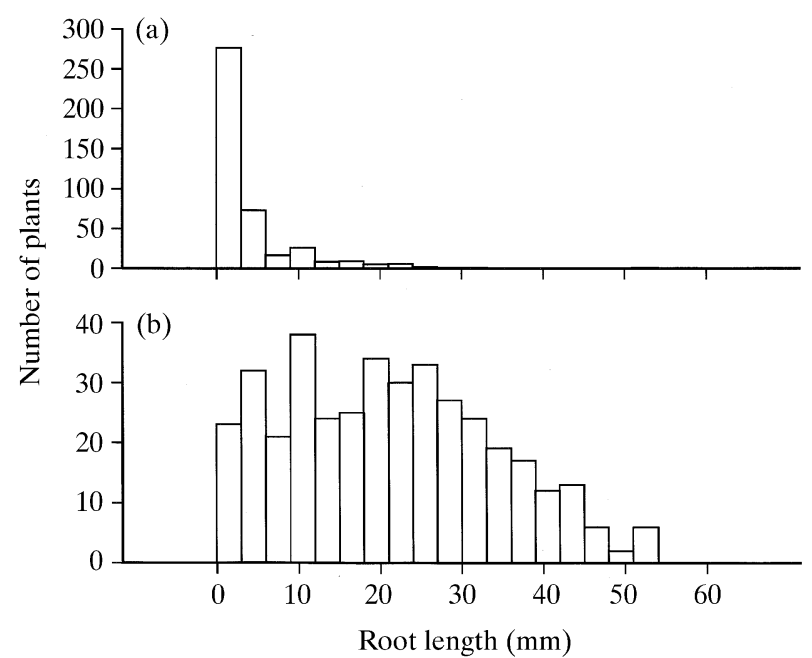

Fig. 2 Distribution of root lengths of Mimulus guttatus at 1 p.p.m. $\mathrm{Cu}$ from $22 \mathrm{~F}_{1}$ families of the cross IsoNT $\times(\mathrm{a})$ LT or (b) HT.

(C) The Genetical Society of Great Britain, Heredity, 80, 760-768.

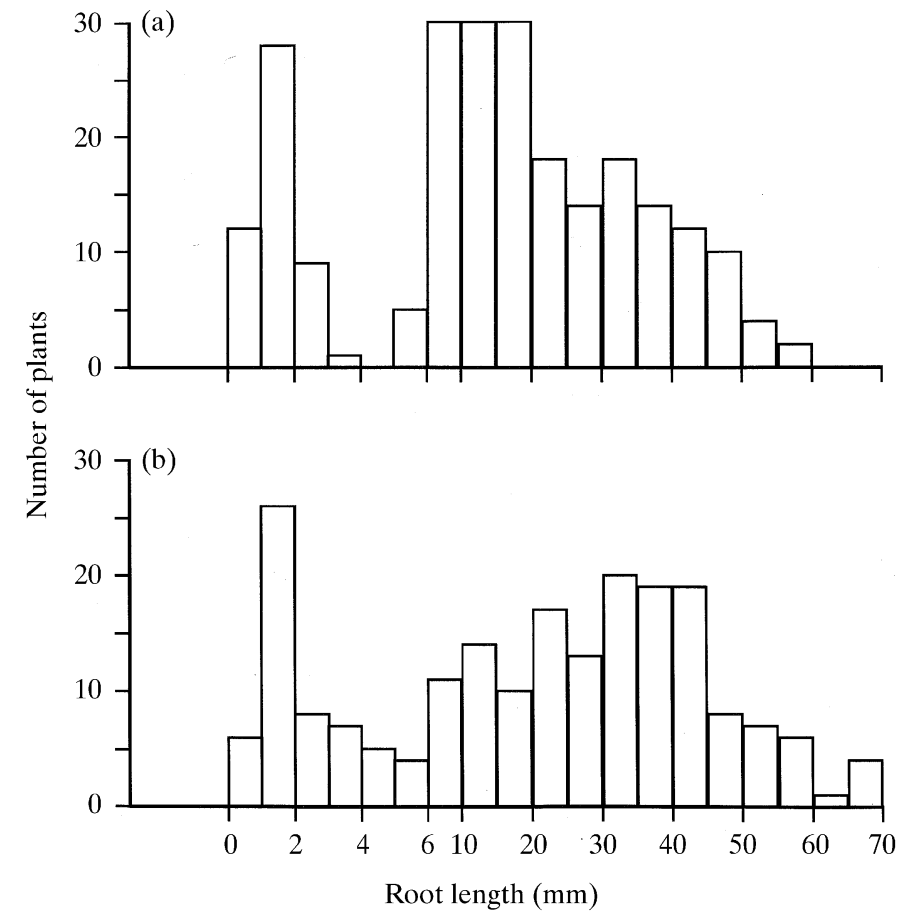

Fig. 3 Distribution of root lengths of Mimulus guttatus at 0.5 p.p.m. $\mathrm{Cu}$ of $\mathrm{F}_{2}$ families of the cross IsoNT $\times(\mathrm{a}) \mathrm{LT}$ or (b) HT.

$2 \mathrm{~mm}$; and (ii) the distributions of the root lengths of the $\mathrm{T}$ plants from both classes of families are different, but substantially overlap.

\section{Crosses involving $\mathrm{F}_{2}$}

The 31 families tested show significant difference in mean root length (Table 1), with differences both between the original crosses and between the $F_{2}$ families derived from them (ANOVA, Table 1). Overall, there is a tendency for those $\mathrm{F}_{2} \mathrm{~S}$ derived from the HT line ( $F_{1}$ families 13, 16 and 22$)$ to have higher means than those $(1,3$ and 10$)$ from LT. Note, however, that the $\mathrm{F}_{2} \mathrm{~S}$ from family 17 all produce low family means, and consequently the overall difference between the LT and HT families is not significant (Table 1).

The differences in means seen in Table 1 are illustrated in Fig. 4. These histograms pool all the families within original crosses, and the differences in pattern between histograms are therefore caused by genetic differences. A plant that is able to produce a root of more than about $10 \mathrm{~mm}$ in this concentration of copper is showing considerable tolerance. The recurrent tester plant (Fig. 4a) shows 
rather low tolerance at this level, and all its roots are shorter than $10 \mathrm{~mm}$. Families 1 and 17 (Fig. 4c,h) also have very few individuals with roots longer than $10 \mathrm{~mm}$, whereas families 13 and 16 (Fig. 4f,g) contain substantial numbers of plants displaying good tolerance with long roots.

\section{Crosses involving $\mathrm{F}_{3}$ plants}

The six $\mathrm{F}_{3} \mathrm{~s}$ tested were chosen so that they spanned the range of variation seen in the $\mathrm{F}_{2}$. The results are given in Table 2 and Fig. 5. The six $F_{3}$ families differ both from each other, and from the distribution shown by the selfs of the recurrent $\mathrm{T}$ plant (Fig. $5 \mathrm{~h}$ ). The families derived from the different $\mathrm{F}_{3} \mathrm{~s}$ differ substantially in mean (Table 2; see between $\mathrm{F}_{3}$ term in ANOVA). There is less variation between the families within the $F_{3}$ s. Family $17 / 13$ is very variable. Of the other five families, only one has just formally significant between-family variance when tested by ANOVA.

\section{Discussion}

Macnair (1983) showed that the difference between copper tolerant and nontolerant plants was primarily caused by a major gene, and he subsequently backcrossed this gene repeatedly to a nontolerant population to produce lines that were essentially isogenic apart from this gene (Strange \& Macnair, 1991). These plants were substantially less tolerant than native mine plants and there is considerable variation amongst different plants collected in the field (Macnair et al., 1993). The suggestion was made therefore that the differences observed in degree of tolerance resulted from modifier genes.

In this paper we have specifically tested for the presence of hypostatic modifiers. From $\mathrm{T} \times \mathrm{NT} \mathrm{F}_{2} \mathrm{~S}$ made using a single NT parent, and T parents with varying degrees of tolerance, we have selected NT plants and tested whether they differ in their ability to enhance the tolerance of the progeny produced when crossed to a single low-tolerant parent. The data clearly show that although these plants had the

Table 1 Mean root length at 1 p.p.m. Cu of 31 families of Mimulus guttatus produced by crossing NT $\mathrm{F}_{2}$ individuals to a single tolerant tester plant (plant E). Only families derived from plants whose NT status was confirmed by growing up their selfed progeny and testing at 0.5 p.p.m. are included. $N$ : number of plants tested. Also given is the nested ANovA of log-transformed root length

\begin{tabular}{|c|c|c|c|c|c|c|c|}
\hline Cross & $N$ & Mean & SE & Cross & $N$ & Mean & SE \\
\hline$E \times 1 / 9$ & 56 & 4.88 & 0.36 & $E \times 16 / 24$ & 55 & 10.82 & 1.73 \\
\hline$E \times 1 / 20$ & 49 & 1.47 & 0.16 & $E \times 16 / 17$ & 52 & 6.90 & 1.18 \\
\hline$E \times 1 / 35$ & 49 & 1.88 & 0.27 & $E \times 16 / 6$ & 54 & 11.30 & 1.47 \\
\hline$E \times 3 / 28$ & 48 & 6.17 & 1.15 & $E \times 16 / 10$ & 54 & 5.54 & 1.12 \\
\hline $\mathrm{E} \times 3 / 10$ & 36 & 2.44 & 0.47 & $E \times 16 / 36$ & 48 & 8.40 & 1.37 \\
\hline$E \times 3 / 43$ & 46 & 4.90 & 0.84 & $E \times 16 / 35$ & 47 & 4.09 & 0.60 \\
\hline$E \times 3 / 48$ & 56 & 5.05 & 1.08 & $E \times 17 / 15$ & 54 & 2.87 & 0.44 \\
\hline$E \times 10 / 4$ & 57 & 4.56 & 0.69 & $E \times 17 / 1$ & 55 & 2.76 & 0.37 \\
\hline$E \times 10 / 18$ & 59 & 4.14 & 0.58 & $E \times 17 / 13$ & 45 & 3.09 & 0.51 \\
\hline$E \times 10 / 19$ & 54 & 2.32 & 0.23 & $E \times 17 / 6$ & 50 & 2.72 & 0.29 \\
\hline$E \times 13 / 32$ & 53 & 8.19 & 1.25 & $E \times 17 / 21$ & 56 & 2.04 & 0.20 \\
\hline$E \times 13 / 48$ & 11 & 8.82 & 1.95 & $\mathrm{E} \times 22 / 30$ & 56 & 5.21 & 0.80 \\
\hline$E \times 13 / 49$ & 50 & 10.16 & 1.54 & $E \times 22 / 21$ & 52 & 3.96 & 0.72 \\
\hline$E \times 13 / 42$ & 54 & 5.72 & 1.16 & $E \times 22 / 23$ & 58 & 5.50 & 0.83 \\
\hline \multirow[t]{2}{*}{$E \times 13 / 14$} & 42 & 12.74 & 2.21 & $\mathrm{E} \times 22 / 3$ & 41 & 3.59 & 0.68 \\
\hline & & & & $E \times 22 / 1$ & 49 & 2.69 & 0.56 \\
\hline \multicolumn{8}{|c|}{ Analysis of Variance: } \\
\hline \multicolumn{3}{|c|}{ Source } & SS & d.f. & MS & $F$ & $P$ \\
\hline \multicolumn{3}{|c|}{ Between LT vs. HT selections } & 15.1 & 1 & 15.1 & 0.9 & 0.28 \\
\hline \multicolumn{3}{|c|}{$\begin{array}{l}\text { Between original } F_{1} \text { families within } \\
\text { selections }\end{array}$} & 87.0 & 5 & 17.4 & 4.35 & $<0.001$ \\
\hline \multicolumn{3}{|c|}{$\begin{array}{l}\text { Between } F_{2} \text { crosses within } F_{1} \text { family } \\
\text { and selection }\end{array}$} & 96.8 & 24 & 4.0 & 4.21 & 0.03 \\
\hline \multicolumn{3}{|c|}{ Within families } & 1446.1 & 1515 & 0.95 & & \\
\hline
\end{tabular}


Fig. 4 Distribution of root lengths at 1.0 p.p.m. $\mathrm{Cu}$ of crosses between $\mathrm{F}_{2}$ NT Mimulus guttatus from seven different $\mathrm{F}_{2}$ families and a single IsoT (plant E), as well as the distribution of root lengths of cuttings of the IsoT and of the pooled progeny of $\mathrm{T}_{2} \mathrm{~S}$ crossed to IsoT (plant E). (a) IsoT: cuttings of plant E; (b) Tol: pooled progeny of $11 \mathrm{E} \times \mathrm{T}$ crosses from all seven $\mathrm{F}_{2}$ families; (c)-(i) pooled progenies of the $\mathrm{E} \times \mathrm{NT}$ crosses from families as indicated. The numbers of the families and individuals tested are given in Table 1.
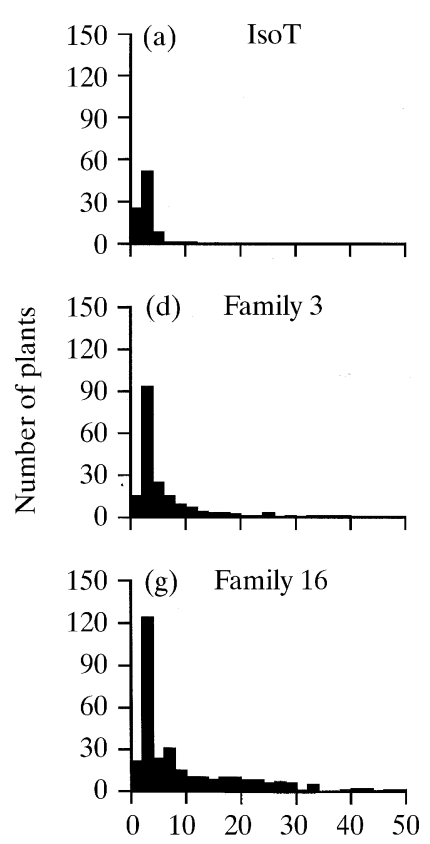

(b)

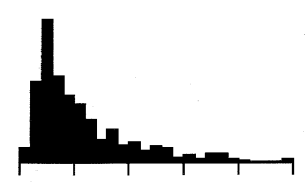

(e) Family 10

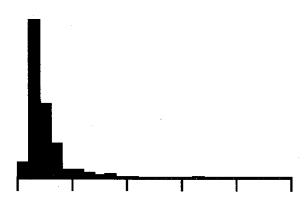

(h) Family 17

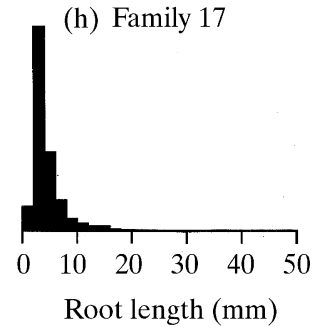

(c) Family 1

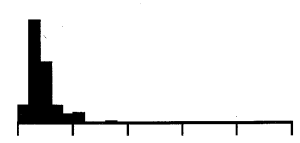

(f) Family 13

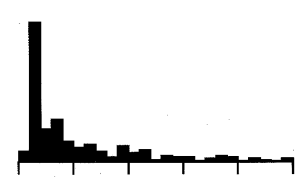

(i) Family 22

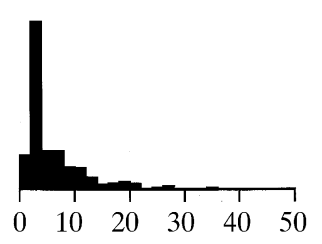

same phenotype themselves, and produced identical offspring distributions when selfed, they differed in the phenotype distribution of their offspring when crossed to the tolerant tester. This must be because of differences in their genotype at hypostatic loci modifying tolerance. Because the original NT parent could have been heterozygous at any modifier loci, it is formally not possible to ascribe all the variation seen between families tested in these experiments to the differences between the HT and LT selection lines. However, the large difference in mean tolerance seen in both the $F_{1} s$ and $F_{2} s$ (Figs 2 and 3) must be caused by variation in modifiers between the lines, and it is probable that the variation introduced into the crossing programme from this source exceeds that from the possible heterozygosity of the original NT parent.

The main differences revealed in the tolerance of the families displayed in Figs 2, 4 and 5 is in the distribution of plants with longer root lengths. Plants able to produce good roots in this highly toxic environment are clearly tolerant of the metal. If we take $10 \mathrm{~mm}$ as an arbitrary cut-off distinguishing such highly tolerant plants, we can compare the proportions of plants in each histogram exceeding this value. Some families have only about $5 \%$ (the $\mathrm{T} \times \mathrm{F}_{2}$ families 1, 10 and 17: Fig. 4c,e,h; and $\mathrm{T} \times \mathrm{F}_{3}$ family 1/20: Fig. 5a). In contrast, in some families over $33 \%$ of individuals show this high-tolerance phenotype $\left(\mathrm{T} \times \mathrm{F}_{2}\right.$ families 13 and 16: Fig. 4f,g; and the $\mathrm{T} \times \mathrm{F}_{3}$ families 13/50, 22/30, 13/14 and 16/24:
Fig. 5c-f). The other histograms lie between these two extremes. These comparisons should be treated with caution, because each histogram is made up from plants from several, normally heterogeneous, families. However, the differences are sufficiently large that the overall pattern is robust. It should be noted that whereas all the families that have the highest mean and proportion of long-rooted individuals derive originally from the HT selection line, other families from this line have a very low proportion (e.g. $\mathrm{T} \times \mathrm{F}_{2}$ 17, Fig. 4h), and the families from the LT line do not all produce families of very low tolerance. This between-family heterogeneity within both HT and LT lines indicates that both lines are evidently still segregating for the modifier genes, as indeed has been shown by the continued response to selection shown by these lines (Harper et al., 1997a). Note that none of the $\mathrm{F}_{2}$ or $\mathrm{F}_{3}$ families approaches the tolerance of the HT $F_{1}$ (Fig. 2), which has $80.3 \%$ of individuals with roots longer than $10 \mathrm{~mm}$.

There is no indication from these data that there is only a single modifier locus segregating in these crosses. The varied pattern of histograms, and the fact that, although some families have a mean tolerance profile very similar to the $\mathrm{NT} \times \mathrm{LT} \mathrm{F}_{1}$, none approaches that of the $\mathrm{NT} \times \mathrm{HT} \mathrm{F}_{1}$ (Fig. 2), would suggest that more than one modifier gene is involved in producing the difference between the LT and HT lines.

It is necessary to exclude the possibility that the modifiers studied here have nothing to do with toler- 
ance, but are simply rooting genes. There is evidence from the selection lines (Macnair et al., 1993; Harper et al., 1997a) that the selection for higher tolerance has also selected for longer roots in a normal nutrient solution, and for a greater tendency for HT plants to form aerial roots (Harper et al., 1997a). These two factors may not be independent (i.e. a plant that roots more easily may have longer roots because it roots earlier in a nutrient solution). However, whereas the HT plants may be somewhat more 'rooty' than the LT in uncontaminated solutions, there is no doubt that they are also substantially more tolerant in contaminated solutions, having very differently shaped dose-response curves and higher $\mathrm{EC}_{100} \mathrm{~s}$ (Macnair et al., 1993; Harper et al., 1997a). The difference in mean root length in normal solution between the high and low lines from which all the families studied here were derived was $10.6 \mathrm{~mm}$, whereas the difference at 1 p.p.m. $\mathrm{Cu}$ was $32.4 \mathrm{~mm}$ (Macnair et al., 1993).
Thus the ability to form long roots at 1 p.p.m. is much more associated with a plant's tolerance than with its innate root growth rate. As we have seen, the major differences between the families in this study are in the proportions of long-rooted plants. This suggests that we are studying genuine modifiers of tolerance, rather than simply root-length genes.

In addition, a gene that unconditionally increased root length or increased rate of root initiation, would affect both $\mathrm{T}$ and NT plants, and should manifest itself as a nonspecific modifier. There is some evidence that there may be a nonspecific modifier segregating in the $F_{2}$. The crosses reported here specifically tested for hypostatic modifiers; any modifier that enhanced the tolerance of NT plants so that their status was doubtful would not have been included. We noted, however, that there was some suggestion in the $F_{2}$ of the HT cross that the NT plants included some longer-rooted plants than the NT plants of the LT cross. One of the NT $\mathrm{F}_{2} \mathrm{~S}$ of

Table 2 Mean root lengths of Mimulus guttatus families produced by crossing $\mathrm{F}_{3} \mathrm{~s}$ to the tolerant plant $\mathrm{J}$. The overall mean for each set of $\mathrm{F}_{3} \mathrm{~s}$ is given, with the $F$-value from the ANOvA testing the $\mathrm{H}_{\mathrm{o}}$ that all the means are the same. Also given is the overall nested ANOVA. All ANOvAs use a log-transformation of the data, which normalizes the residuals

\begin{tabular}{|c|c|c|c|c|c|c|c|}
\hline Cross & $N$ & Mean & SE & Cross & $N$ & Mean & SE \\
\hline $\mathrm{J} \times 1 / 20 / 3$ & 55 & 1.95 & 0.23 & $\mathrm{~J} \times 22 / 30 / 1$ & 62 & 8.05 & 1.11 \\
\hline $\mathrm{J} \times 1 / 20 / 5$ & 50 & 2.28 & 0.28 & $\mathrm{~J} \times 22 / 30 / 6$ & 50 & 7.48 & 1.04 \\
\hline $\mathrm{J} \times 1 / 20 / 6$ & 50 & 2.18 & 0.31 & $\mathrm{~J} \times 22 / 30 / 7$ & 49 & 9.35 & 1.34 \\
\hline $\mathrm{J} \times 1 / 20 / 8$ & 54 & 2.74 & 0.50 & $\mathrm{~J} \times 22 / 30 / 8$ & 49 & 4.65 & 0.72 \\
\hline $\mathrm{J} \times 1 / 20 / 9$ & 49 & 3.22 & 0.53 & $\mathrm{~J} \times 22 / 30 / 9$ & 37 & 6.46 & 1.27 \\
\hline \multicolumn{4}{|l|}{$F_{4,253}=1.47, \mathrm{NS}$} & $\begin{array}{l}\text { Overall } \\
F_{4,242}=1.57, \mathrm{NS}\end{array}$ & 247 & 7.28 & 0.51 \\
\hline $\mathrm{J} \times 17 / 13 / 1$ & 51 & 1.45 & 0.16 & $\mathrm{~J} \times 13 / 14 / 1$ & 51 & 6.67 & 1.02 \\
\hline $\mathbf{J} \times 17 / 13 / 6$ & 48 & 1.58 & 0.22 & $\mathbf{J} \times 13 / 14 / 3$ & 46 & 8.11 & 1.20 \\
\hline $\mathrm{J} \times 17 / 13 / 8$ & 47 & 2.96 & 0.43 & $\mathrm{~J} \times 13 / 14 / 6$ & 43 & 9.37 & 1.18 \\
\hline $\mathrm{J} \times 17 / 13 / 9$ & 52 & 7.31 & 1.02 & $\mathbf{J} \times 13 / 14 / 9$ & 49 & 8.04 & 1.07 \\
\hline $\mathbf{J} \times 17 / 13 / 10$ & 52 & 5.37 & 0.72 & $\mathrm{~J} \times 13 / 14 / 10$ & 46 & 6.13 & 0.84 \\
\hline \multicolumn{4}{|l|}{$F_{4,245}=14.88^{* * *}$} & \multicolumn{4}{|l|}{$F_{4,230}=1.52, \mathrm{NS}$} \\
\hline $\mathbf{J} \times 13 / 50 / 1$ & 48 & 4.31 & 0.74 & $\mathrm{~J} \times 16 / 24 / 2$ & 57 & 6.14 & 0.98 \\
\hline $\mathrm{J} \times 13 / 50 / 3$ & 49 & 4.69 & 0.90 & $\mathrm{~J} \times 16 / 24 / 3$ & 46 & 4.96 & 0.88 \\
\hline $\mathrm{J} \times 13 / 50 / 4$ & 56 & 6.18 & 0.88 & $\mathrm{~J} \times 16 / 24 / 4$ & 48 & 9.73 & 1.43 \\
\hline $\mathbf{J} \times 13 / 50 / 2$ & 48 & 5.21 & 0.86 & $\mathrm{~J} \times 16 / 24 / 7$ & 50 & 7.00 & 0.89 \\
\hline $\mathrm{J} \times 13 / 50 / 6$ & 50 & 7.38 & 1.05 & $\mathrm{~J} \times 16 / 24 / 9$ & 49 & 7.31 & 1.00 \\
\hline $\begin{array}{l}\text { Overall } \\
F_{4,247}=2.73^{*}\end{array}$ & 251 & 5.59 & 0.41 & $\begin{array}{l}\text { Overall } \\
F_{4,245}=1.80, \mathrm{NS}\end{array}$ & 250 & 7.01 & 0.48 \\
\hline \multicolumn{8}{|l|}{ Overall ANOVA: } \\
\hline \multicolumn{3}{|l|}{ Source } & SS & d.f. & MS & $\mathrm{F}$ & $P$ \\
\hline \multicolumn{3}{|c|}{ Between $F_{3}$ crosses } & 120.7 & 5 & 24.1 & 7.1 & $<0.001$ \\
\hline \multicolumn{3}{|c|}{ Between families within $\mathrm{F}_{3} \mathrm{~S}$} & 81.2 & 24 & 3.38 & 3.4 & $<0.001$ \\
\hline \multicolumn{3}{|c|}{ Within families } & 1429.9 & 1461 & 0.98 & & \\
\hline
\end{tabular}

NS, not significant at the 0.05 level; ${ }^{*} P<0.05,{ }^{* * *} P<0.001$. 
Fig. 5 Distribution of root lengths at 1.0 p.p.m. $\mathrm{Cu}$ of crosses between five $\mathrm{F}_{3}$ Mimulus guttatus from each of six $\mathrm{F}_{2}$ NT individuals and a single IsoT plant. (a)-(f) Pooled progeny from families as indicated. (g) The pooled progeny from the selfs of all six $\mathrm{F}_{2}$ individuals. (h) IsoT: the selfed progeny of the recurrent tolerant plant.

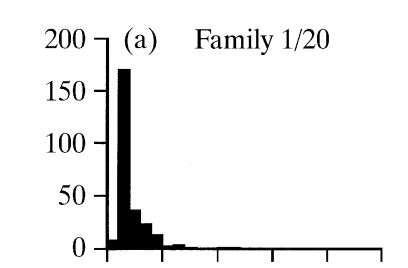

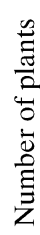
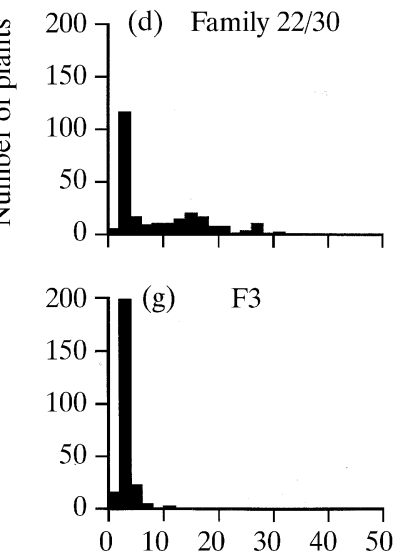

(b) Family $17 / 13$

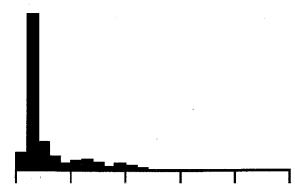

(e) Family 13/14

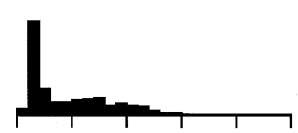

(h) IsoT

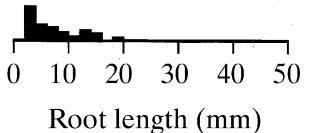

(c) Family $13 / 50$

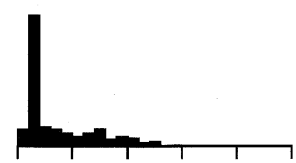

(f) Family 16/24

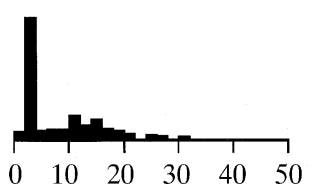

family 13 tested produced a ratio on selfing of seven 'tolerant' plants and 21 NTs (and was therefore not included in Table 1); this family would be consistent with there being an additive modifier that produced a very low-level tolerance in the absence of the $T$ gene. The ratio of $21: 7$ obviously suggests a single gene, with the effect on tolerance being recessive. However, there is no evidence of this gene affecting the distribution of root lengths in the tolerant progeny of the $\mathrm{F}_{2} \mathrm{~s}$. If there were a gene of discernible effect segregating in the $\mathrm{HT} \mathrm{F}_{2}$ but not in the LT $\mathrm{F}_{2}$, then we would predict that the tolerant plants of the HT $\mathrm{F}_{2}$ should have a greater variance than those of the LT $\mathrm{F}_{2}$. The HT variance is indeed slightly larger, but not significantly so $\left(F_{151,115}=1.21\right.$, $P=0.15)$, and this increase is explained by the difference in mean: the coefficient of variation of the LTs is larger than that of the HTs.

The mechanism of copper tolerance is still not understood, with various different mechanisms proposed in the literature (Meharg, 1994). Macnair (1983, 1993) argued that major gene control of tolerance indicated that there was a single, primary molecular change that rendered the plants tolerant, and that this change is the one that needs to be identified in defining the mechanism of tolerance. However, the variation in degree of tolerance noted in many studies of metal tolerant plants allowed the possibility that the major gene studied by Macnair
(1983) was simply one of several possible genes, with different genes controlling different mechanisms. The data presented here do not support this latter interpretation. The hypostasy of the modifiers studied in this paper implies that they purely act to enhance the tolerance produced by the major gene, and that their gene products cannot of themselves affect the tolerance phenotype in the absence of the major gene. The recessive additive gene, if confirmed, might indicate that a low level of tolerance can be achieved by an alternative mechanism to that given by the major gene.

Macnair et al. (1993) found that the clines for the tolerance gene were rather gentle at the Copperopolis mine, CA. Subpopulations well away from the main area of contamination had $100 \%$ tolerant individuals. In contrast, the degree of tolerance shown by these plants declined much more steeply as the collections were sampled away from the main axis of the mine. This result is surprising, if the modifiers' only effect is to increase tolerance. Theories of disruptive selection predict (Endler, 1977) that specific modifiers should be able to spread throughout the cline, and that thus they should have a gentler cline than the major gene. However, this theory is based on the assumption that the disruptive selection acts on the final observed phenotype, and that thus the selective value, say, $t t M M$ is the same as ttmm (because they have the same pheno- 
type). The observed clinal pattern suggests that selection may act more strongly against the modifiers than against the tolerance gene in areas of low copper contamination. We have been testing this hypothesis (Harper et al., 1997a,b) but so far have not been able to show any convincing disadvantage to either tolerance or the modifiers of tolerance.

\section{Acknow ledgements}

This work was supported by the Natural Environment Research Council grant no. GR3/8306'A' to M.R.M., receipt of which is gratefully acknowledged. We thank Phil Goodson for assistance in plant cultivation, and two anonymous referees whose comments led to the improvement of this manuscript.

\section{References}

ANTONOVICS, J., BRADSHAw, A. D. AND TURNER, R. G. 1971. Heavy metal tolerance in plants. Adv. Ecol. Res., 7, $1-85$.

BAKer, A. J. M. 1987. Metal tolerance. New Phytol., 106 (Suppl.), 93-111.

CUMming, J. R. AND TOMSETt, A. B. 1992. Metal tolerance in plants: signal transduction and acclimation mechanisms. In: Adriano, D.C. (ed.) Biogeochemistry of Trace Metals, pp. 329-364. Lewis Publishers, Boca Raton, FL.

DE VOS, C. H. R., VOOIJS, R., SCHAT, H. AND ERNST, W. H. O. 1989. Copper-induced damage to the permeability barrier in roots of Silene cucubalus. J. Plant Physiol., 135, 165-169.

ENDler, J. A. 1977. Geographic Variation, Speciation, and Clines. Princeton University Press, Princeton, NJ.

GARTSIDE, D. W. AND McNeILly, T. 1974. Genetic studies in heavy metal tolerant plants I. Genetics of zinc tolerance in Anthoxanthum odoratum. Heredity, 32, 287-297.

HARPER, F. A., SMITH, S. E. AND MACNAIR, M. R. 1997a. Where is the cost in copper tolerance in Mimulus guttatus? Testing the trade-off hypothesis. Funct. Ecol., 11, $764-774$

HARPER, F. A., SMITH, S. E. AND MACNAIR, M. R. 1997b. Can an increased copper requirement in copper-tolerant Mimulus guttatus explain the cost of tolerance? 1. Vegetative growth. New Phytol., 136, 455-467.
KAMPFENKEL, K., KUSHNIR, S., BABIYCHUK, E., INZE, D. AND VAN MONTAGU, M. 1995. Molecular characterization of a putative Arabidopsis thaliana copper transporter and its yeast homologue. J. Biol. Chem., 270, 28479-28486.

MACNAIR, M. R. 1983. The genetic control. of copper tolerance in the yellow monkey flower, Mimulus guttatus. Heredity, 50, 283-359.

MACNAIR, M. R. 1993. Tansley Review no. 49: The genetics of metal tolerance in vascular plants. New Phytol., 124, 541-559.

MACNAIR, M. R. AND BAKER, A. J. M. 1994. Metal tolerance in plants: evolutionary aspects. In: Farago, M. E. (ed.) Plants and the Chemical Elements, pp. 67-86.VCH, Weinheim.

MACNAIR, M. R., CUMBES, Q. J. AND SMITH, S. 1993. The heritability and distribution of variation in degree of copper tolerance in Mimulus guttatus on a copper mine at Copperopolis, California. Heredity, 71, 445-455.

MEHARG, A. A. 1994. Integrated tolerance mechanisms: constitutive and adaptive plant responses to elevated metal concentrations in the environment. Pl. Cell Env., 17, 989-993.

MURPHY, A. AND TAIZ, L. 1995. Comparison of metallothionein gene-expression and non-protein thiols in 10 Arabidopsis genotypes - correlation with copper tolerance. Pl. Physiol., 109, 945-954.

SCHAT, H. AND TEN BOOKUM, w. M. 1992. Genetic control. of copper tolerance in Silene vulgaris. Heredity, 68, 219-229.

SCHAT, H., KUIPER, E., TEN BOOKUM, W. M. AND VOOIJS, R. 1993. A general model for the genetic control of copper tolerance in Silene vulgaris: evidence from crosses between plants from different tolerant populations. Heredity, 70, 142-147.

SOKAL, R. R. AND ROHLF, F. J. 1995. Biometry, 3rd edn. Freeman, New York.

STEFFENS, J. C. 1990. The heavy metal-binding peptides of plants. Ann. Rev. Pl. Physiol. Pl. Mol. Biol., 41, 533-575.

STRANGE, J. AND MACNAIR, M. R. 1991. Evidence for a role for the cell membrane in copper tolerance of Mimulus guttatus. New Phytol., 119, 383-388.

TURNER, J. R. G. 1977. Butterfly mimicry: the genetical evolution of an adaptation. Evol. Biol., 10, 163-206.

WILKINS, D. A. 1960. The measurement and genetical analysis of lead tolerance in Festuca ovina. Rep. Scott. Pl. Breed. Stn., 85-98.

ZENK, M. H. 1996. Heavy metal detoxification in higher plants: A review. Gene, 179, 21-30. 